\title{
Functional comparison between the BuMA Supreme biodegradable polymer sirolimus-eluting stent and a durable polymer zotarolimus-eluting coronary stent using quantitative flow ratio: PIONEER QFR substudy
}

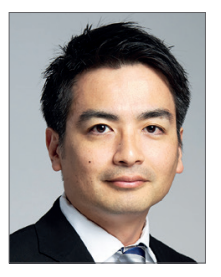

Taku Asano ${ }^{1,2}$, MD; Yuki Katagiri ${ }^{1}, \mathrm{MD}$; Carlos Collet ${ }^{1}, \mathrm{MD}$; Erhan Tenekecioglu ${ }^{3}, \mathrm{MD}$; Yosuke Miyazaki ${ }^{3}, \mathrm{MD}, \mathrm{PhD}$; Yohei Sotomi ${ }^{1}, \mathrm{MD}$; Giovanni Amoroso ${ }^{4}, \mathrm{MD}, \mathrm{PhD}$; Adel Aminian ${ }^{5}, \mathrm{MD}$; Salvatore Brugaletta ${ }^{6}, \mathrm{MD}, \mathrm{PhD}$; Mathias Vrolix ${ }^{7}, \mathrm{MD}$; Rosana Hernandez-Antolín ${ }^{8}, \mathrm{MD}, \mathrm{PhD}$; Pim van de Harst' ${ }^{9}, 10, \mathrm{MD}, \mathrm{PhD}$; Andres Iñiguez ${ }^{11}, \mathrm{MD}, \mathrm{PhD}$; Luc Janssens $^{12}$, MD; Pieter C. Smits ${ }^{13}, \mathrm{MD}, \mathrm{PhD}$; Joanna Wykrzkowska ${ }^{1}, \mathrm{MD}, \mathrm{PhD}$; Vasco Gama Ribeiro ${ }^{14}$, MD; Helder Pereira ${ }^{15}$, MD; Pedro Canas da Silva ${ }^{16}$, MD; Jan J. Piek ${ }^{1}, \mathrm{MD}$, PhD; Johan H.C. Reiber ${ }^{17}$, PhD; Clemens von Birgelen ${ }^{18}$, MD, PhD; Manel Sabate ${ }^{6}$, MD, PhD; Yoshinobu Onuma ${ }^{3,19 *}, \mathrm{MD}, \mathrm{PhD}$; Patrick W. Serruys ${ }^{20}, \mathrm{MD}, \mathrm{PhD}$

1. Academic Medical Center, University of Amsterdam, Amsterdam, the Netherlands; 2. Department of Cardiology, St. Luke's International Hospital, Tokyo, Japan; 3. Thoraxcenter, Erasmus Medical Center, Rotterdam, the Netherlands; 4. Onze Lieve Vrouwe Gasthuis, Amsterdam, the Netherlands; 5. Centre Hospitalier Universitaire de Charleroi, Charleroi, Belgium; 6. Clinic University Hospital, Cardiovascular Clinic Institute, Institut d'Investigacions Biomèdiques August Pi i Sunyer (IDIBAPS), Barcelona, Spain; 7. Oost Limburg Hospital, Genk, Belgium; 8. University Hospital Ramón y Cajal, Madrid, Spain; 9. University of Groningen, Groningen, the Netherlands; 10. University Medical Center Groningen, Groningen, the Netherlands; 11. Hospital Alvaro Cunqueiro, Vigo, Spain; 12. Imelda Hospital Bonheiden, Bonheiden, Belgium, 13. Maasstad Hospital, Rotterdam, the Netherlands; 14. Gaia/Espinho Hospital Centers, Oporto, Portugal; 15. Hospital Garcia de Orta, Almada, Portugal; 16. Santa Maria University Hospital - North Lisbon Hospital Center, Lisbon, Portugal; 17. Department of Radiology, Leiden University Medical Center, Leiden, the Netherlands; 18. Thoraxcentrum Twente, Enschede, the Netherlands; 19. Cardialysis, Rotterdam, the Netherlands; 20. International Centre for Circulatory Health, NHLI, Imperial College London, London, United Kingdom

GUEST EDITOR: Michail I. Papafaklis, MD, PhD, FESC; Department of Interventional Cardiology, Barts Heart Centre, St Bartholomew's Hospital, London, United Kingdom

This paper also includes supplementary data published online at: http://www.pcronline.com/eurointervention/138th_issue/100

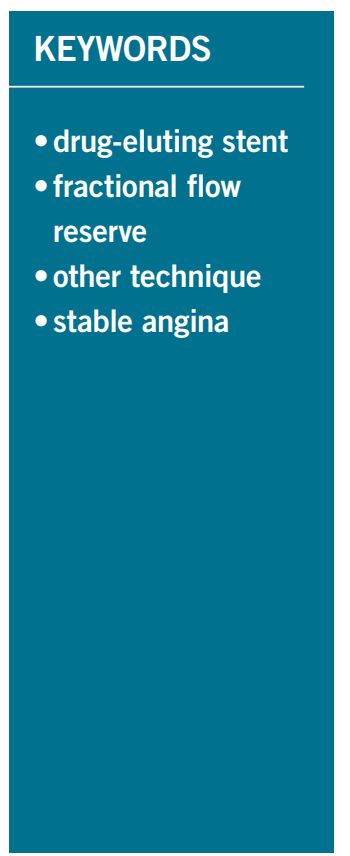

\section{Abstract}

Aims: Quantitative flow ratio (QFR) based on three-dimensional quantitative coronary angiography (3DQCA) is a novel method to assess physiological functionality after treatment with stents. The current study aimed to evaluate the difference in physiological functionality nine months after implantation of a bioresorbable polymer-based sirolimus-eluting stent with an electrografting base layer (BuMA Supreme: B-SES) versus a durable polymer-based zotarolimus-eluting stent (Resolute: R-ZES).

Methods and results: The current post hoc analysis was performed in the PIONEER randomised trial (1:1 randomisation to B-SES [83 patients/95 lesions] and R-ZES [87 patients/101 lesions]). QFR was measured in stented vessels in both arms at preprocedural, post-procedural and nine-month angiography without pharmacologically induced hyperaemia (contrast QFR). At nine months, both the values of QFR distal to the stent (B-SES: $0.89 \pm 0.10$ vs. R-ZES: $0.89 \pm 0.11, \mathrm{p}=0.97$ ) and the number of vessels with $\mathrm{QFR} \leq 0.8$ were not significantly different between the two groups $(11.0 \%$ vs. $12.8 \%, \mathrm{p}=0.72)$, while the in-stent binary restenosis rate was also comparable $(3.7 \%$ vs. $3.5 \%, \mathrm{p}=1.00)$. QFR gradient across the device $(\Delta \mathrm{QFR})$ at nine months was also similar between the groups (B-SES: $0.03 \pm 0.04$ vs. R-ZES: $0.03 \pm 0.07, \mathrm{p}=0.95$ ).

Conclusions: Quantitative flow assessment nine months after stenting did not differ between B-SES and R-ZES, despite a significant difference in in-stent late lumen loss.

\footnotetext{
*Corresponding author: Thoraxcenter, Erasmus Medical Center, P.O. Box 2125, 3000 CC Rotterdam, the Netherlands. E-mail:yoshinobuonuma@gmail.com
} 


\section{Abbreviations}

$\triangle$ QFR QFR gradient across the device

AUC area under the receiver operating characteristic curve

DES drug-eluting stent

FFR fractional flow reserve

LLL late lumen loss

QCA quantitative coronary angiography

QFR quantitative flow ratio

SES sirolimus-eluting stent

TLR target lesion revascularisation

ZES zotarolimus-eluting stent

\section{Introduction}

Angiographic late lumen loss (LLL) is considered a reliable discriminator to differentiate the performances of various coronary devices such as balloons, stents and bioresorbable scaffolds ${ }^{1-3}$. However, in the current drug-eluting stent (DES) era, new devices within a very low LLL range have been compared which might have low probabilities of restenotic events, even if there is a statistically significant difference in LLL between the two devices ${ }^{4,5}$. The clinical significance of comparing devices with very low LLL is debatable.

Fractional flow reserve (FFR) has been considered an accurate diagnostic tool due to its capacity to overcome the limitations of angiography in assessing the functional severity of coronary stenosis $^{6}$. An increasing body of evidence supports the safety and efficacy of therapeutic decisions based on FFR in multiple clinical and anatomical settings ${ }^{7-9}$. Quantitative flow ratio (QFR) is a novel approach enabling rapid computation of FFR pullbacks from three-dimensional quantitative coronary angiography (3D-QCA) without using a pressure wire ${ }^{10-13}$. A QFR $\leq 0.80$ with and without hyperaemic computed flow (adenosine-flow QFR and contrastflow QFR) was reported to have favourable diagnostic accuracy in identifying a wire-derived FFR of $\leq 0.80^{10}$.

The PIONEER trial was a randomised trial which compared the biodegradable polymer-based cobalt-chromium ( $\mathrm{CoCr}$ ) platform sirolimus-eluting BuMA ${ }^{\mathrm{TM}}$ Supreme (SINOMED, Tianjin, China) stent with an electrografting base layer (B-SES) with the durable polymer-coated zotarolimus-eluting Resolute ${ }^{\mathrm{TM}}$ stent (R-ZES) (Medtronic, Minneapolis, MN, USA) and aimed to demonstrate the non-inferiority of the B-SES to the R-ZES in terms of nine-month angiographic in-stent LLL. In the current trial, the B-SES did not meet the primary endpoint of non-inferiority ${ }^{14}$. Although the B-SES was significantly inferior to the R-ZES in terms of in-stent LLL $\left(0.29 \pm 0.34 \mathrm{~mm}\right.$ vs. $0.14 \pm 0.37 \mathrm{~mm}, \mathrm{p}_{\text {inferior- }}$ ity $=0.004)$, the incidence of device-oriented cardiovascular events (DoCE) at 12 months was not different between the groups $(4.9 \%$ vs. $5.7 \% \mathrm{p}=1.00)$. The in-stent binary restenosis rate of the B-SES at nine months was also comparable to the R-ZES (3.3\% vs. $4.4 \%$, $\mathrm{p}=1.00$ ). It was questionable whether statistically different LLL values within a low range impact on the functionality of the restenotic stents. The functional significance of different LLL between the B-SES and R-ZES remained to be investigated.
In the current study, we evaluated the physiological functionality of the LLL in both stents with QFR analysis.

\section{Methods}

\section{STUDY DESIGN AND POPULATION}

The current study was a post hoc substudy of the PIONEER trial comparing the B-SES with the R-ZES in patients with coronary artery disease to demonstrate non-inferiority of the B-SES to the R-ZES in terms of nine-month angiographic in-stent LLL. The details of the protocol and the main results of the trial have already been reported elsewhere ${ }^{14}$. The inclusion and exclusion criteria are described in the Supplementary Appendix.

\section{CORONARY ANGIOGRAPHY}

In the PIONEER trial, coronary angiography was repeated at nine-month follow-up. All angiography was preceded by an intracoronary injection of isosorbide dinitrate or nitroglycerine. According to the protocol, target lesions were recorded with at least two projections separated by more than $30^{\circ}$ to obtain proper LLL in matched angiographic views, from which the 3D lumen reconstruction was derived in the current substudy. In the case of target lesion revascularisation (TLR), pre-TLR angiographic data were analysed as follow-up angiography.

\section{D QUANTITATIVE CORONARY ANGIOGRAPHY ANALYSIS}

Off-line 2D-QCA was performed in an independent core laboratory (Cardialysis, Rotterdam, the Netherlands) with the CAAS system, version 5.11 (Pie Medical Imaging, Maastricht, the Netherlands) according to standard protocol. The following QCA parameters were calculated: minimal lumen diameter, reference vessel diameter (interpolated diameter of normal vessel), percent diameter stenosis ([1-minimum lumen diameter/reference vessel diameter] $\times 100$ ) and late lumen loss (difference between the post-procedure and follow-up minimal lumen diameter). Binary restenosis was defined as stenosis of 50 percent or greater in the target lesion or segment at angiographic follow-up. Measurements within the stented segment were defined as the in-stent analysis. The in-segment analysis included both the in-stent segment and the edge segments which were $5 \mathrm{~mm}$ segments proximal or distal to the implantation site.

\section{QUANTITATIVE FLOW RATIO CALCULATION}

Details regarding the QFR calculation method have been reported elsewhere ${ }^{10,15}$. Briefly, the QFR calculation was based on the 3D-QCA reconstructed from two angiographic projections with angles $\geq 25^{\circ}$ apart and volumetric flow rate calculated by using contrast bolus frame count. The 3D-QCA reconstruction and measurements were performed as described previously ${ }^{16}$. The rate of volumetric flow was assessed with a frame count based on the TIMI frame counting method ${ }^{17}$.

The QFRs at pre-procedure, post-procedure and nine-month follow-up were assessed using validated software (QAngio XA 3D research edition 1.0; Medis medical imaging systems bv, Leiden, 
the Netherlands), which received Conformité Européenne (CE) marking certification for clinical usage in April 2017, by two experienced observers (T. Asano and Y. Katagiri). In the current study, the QFR value was computed by using projections without pharmacologically induced hyperaemia (contrast-flow QFR) for the analysis ${ }^{10}$.

The QFR analysis was performed at the distal point of the target vessel (vessel QFR). The distal point was situated at least distally of the last lesion as long as the lumen diameter was more than $2 \mathrm{~mm}$. In the post-procedural and follow-up angiography, QFR gradient across the device $\left(\Delta \mathrm{QFR}_{\mathrm{POST}}\right.$ and $\left.\Delta \mathrm{QFR}_{\mathrm{FU}}\right)$ was also analysed (Figure 1) ${ }^{18}$. For the assessment of the progression of flow limitation within the device at nine months, the difference in $\mathrm{QFR}$ gradient across the device $\left(\Delta \mathrm{QFR}_{\mathrm{FU}}-\Delta \mathrm{QFR}_{\mathrm{POST}}\right)$ was calculated.

\section{STATISTICAL ANALYSIS}

Data are expressed as mean $\pm \mathrm{SD}$ or median and interquartile range with differences ( $95 \%$ confidence interval). Group means for continuous variables with normal distributions were compared using the Student's t-test. Categorical variables were compared using the Pearson's chi-square test or Fisher's exact test, as appropriate. A cubic polynomial regression analysis was performed to correlate LLL and difference in QFR gradient across the device. Statistical significance was assumed at a probability (p) value of
$<0.05$. Statistical analyses were performed with SPSS, Version 24.0.0 (IBM Corp., Armonk, NY, USA).

\section{Results STUDY SUBJECTS}

In the PIONEER trial, a total of 170 patients were included and randomly assigned to undergo treatment with B-SES (83 patients and 95 lesions) or R-ZES (87 patients and 101 lesions). For the QFR analysis, the lesions without two appropriate angiographic projections with angles $\geq 25^{\circ}$ apart or the lesions without data for autocalibration were excluded (Figure 2). All the lesions available for QFR analysis were also analysable by 2D-QCA analysis at each time point. Baseline demographics and procedural characteristics are separately reported in Supplementary Table $1^{14}$.

\section{D-QCA ANALYSIS}

Table 1 summarises the results of 2D-QCA analysis of the population with available QFR. In-stent LLL at nine months was $0.30 \pm 0.34 \mathrm{~mm}$ in the B-SES group versus $0.13 \pm 0.35 \mathrm{~mm}$ in the R-ZES group $(\mathrm{p}=0.004)$. In-stent $\% \mathrm{DS}$ at nine months was $17.0 \pm 12.0 \%$ in the B-SES group and $15.5 \pm 11.6 \%$ in the R-ZES group $(p=0.06)$.

\section{QFR ANALYSIS}

The QFR analysis results are summarised in Table 2. The vessel QFRs at nine months were not significantly different between the

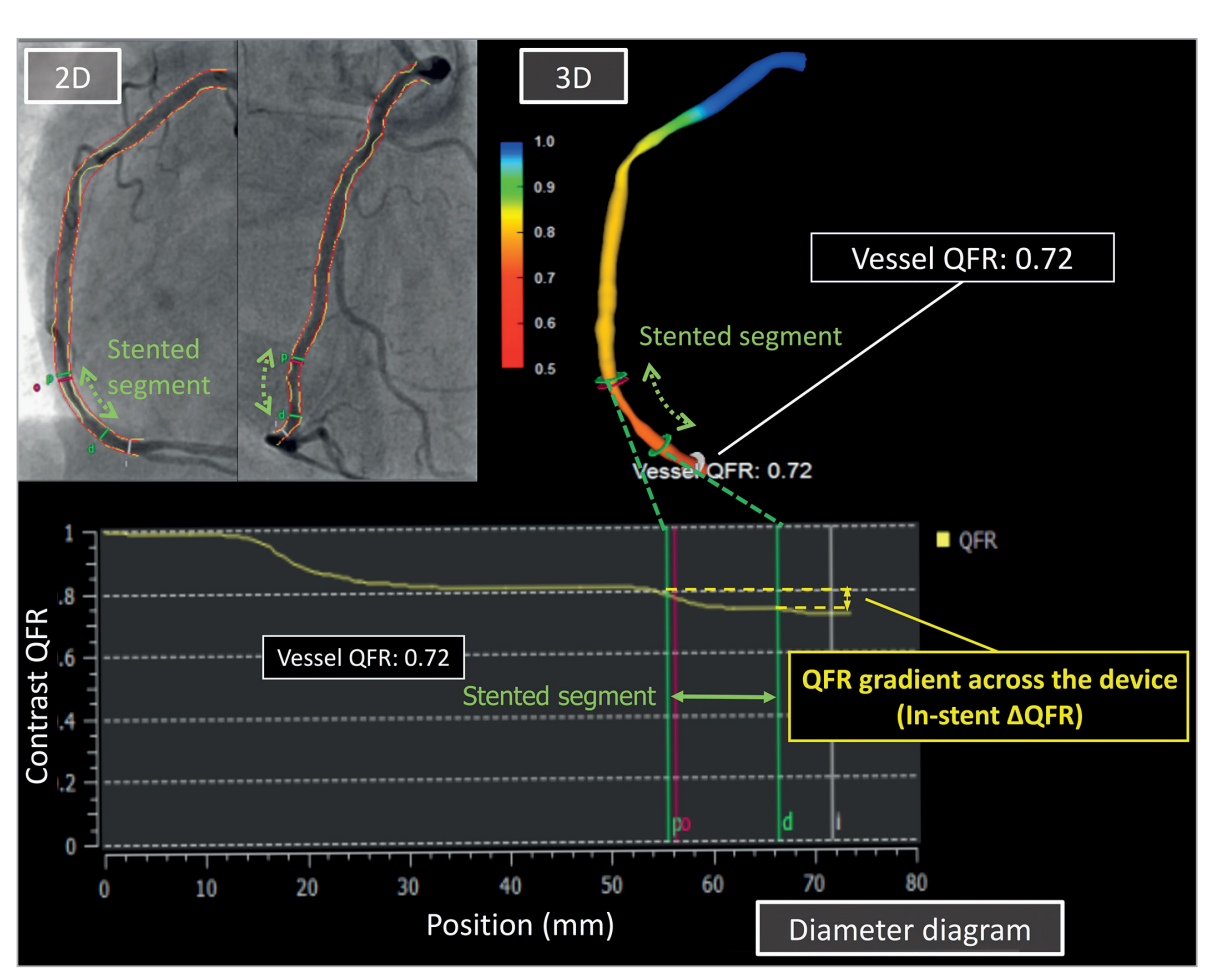

Figure 1. The quantitative flow ratio (QFR) with QAngio XA 3D. QFR calculation was based on the 3D-QCA reconstructed from two angiographic projections with angles $\geq 25^{\circ}$ apart and volumetric flow rate calculated by using contrast bolus frame count. QFR analysis was performed at the distal point of the target vessel (vessel QFR). QFR gradient across the device (in-stent $\triangle Q F R_{P O S T}$ and in-stent $\triangle Q F R_{F L}$ ) was analysed in the post-procedural and follow-up angiography. 


\begin{tabular}{|c|c|}
\hline \multicolumn{2}{|c|}{ PIONEER trial QFR substudy } \\
\hline $\begin{array}{l}\text { BuMA Supreme SES } \\
83 \text { patients } / 95 \text { lesions }\end{array}$ & $\begin{array}{l}\text { Resolute-type ZES } \\
87 \text { patients/101 lesions }\end{array}$ \\
\hline $\begin{array}{l}\text { Pre-procedure Available 2D-QCA (L=92) } \\
\text { Available QFR (L=71) } \\
\text { - No appropriate } 2 \text { projections L=19 } \\
\text { - No autocalibration data L=1 } \\
\text { - Non-analysable (99\% stenosis) L=1 } \\
\text { Applied 2D-QCA (L=71) }\end{array}$ & $\begin{array}{l}\text { Pre-procedure Available 2D-QCA ( } L=95 \text { ) } \\
\text { Available QFR ( } L=84 \text { ) } \\
\quad \text { - No appropriate } 2 \text { projections } L=7 \\
\text { - No autocalibration data } L=3 \\
\text { - Non-analysable (99\% stenosis) } L=1 \\
\text { Applied 2D-QCA ( } L=84 \text { ) }\end{array}$ \\
\hline $\begin{array}{l}\text { Post procedure Available 2D-QCA (L=93) } \\
\text { Available QFR ( } L=78) \\
\quad \text { - No appropriate } 2 \text { projections } L=14 \\
\text { - No autocalibration data } L=1 \\
\text { Applied 2D-QCA }(\mathrm{L}=\mathbf{7 8})\end{array}$ & $\begin{array}{l}\text { Post procedure Available 2D-QCA (L=98) } \\
\text { Available QFR ( } L=86 \text { ) } \\
\quad \text { - No appropriate } 2 \text { projections } L=11 \\
\text { - No autocalibration data } L=1 \\
\text { Applied 2D-QCA ( } L=86 \text { ) }\end{array}$ \\
\hline $\begin{array}{l}\text { Death }(N=1, L=1) \\
\text { Refusal of invasive imaging investigation } \\
(N=4, L=4)\end{array}$ & $\begin{array}{l}\text { Death }(N=2, L=3) \\
\text { Refusal of invasive imaging investigation }(N=5, L=5) \\
\text { Patient did not return for follow-up }(N=1, L=1)\end{array}$ \\
\hline 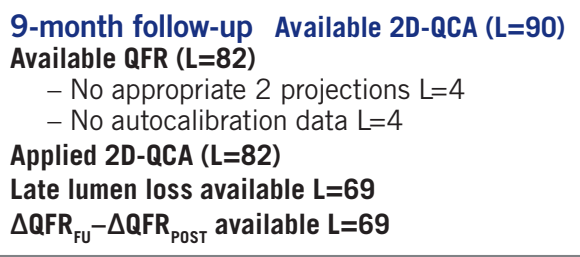 & 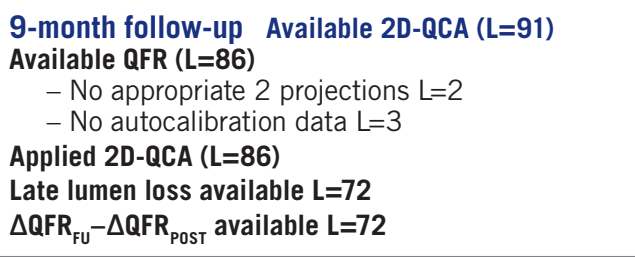 \\
\hline
\end{tabular}

Figure 2. Flow chart of the current study. L: number of lesions; N: number of patients; QCA: quantitative coronary angiography; QFR: quantitative flow ratio; SES: sirolimus-eluting stent; ZES: zotarolimus-eluting stent

two groups (B-SES: $0.89 \pm 0.10$ vs. R-ZES: $0.89 \pm 0.11$, p=0.97). The number of lesions with QFR $\leq 0.8$ was nine $(11.0 \%$ [9/82]) in the B-SES group and $11(12.8 \%[11 / 86])$ in the R-ZES group
( $p=0.72$ ) (Figure 3, Figure 4). The QFR gradient across the device at nine months $\left(\triangle \mathrm{QFR}_{\mathrm{FU}}\right)$ and the difference in QFR gradient across the device $\left(\Delta \mathrm{QFR}_{\mathrm{FU}}-\Delta \mathrm{QFR}_{\mathrm{POST}}\right)$ were also similar between the

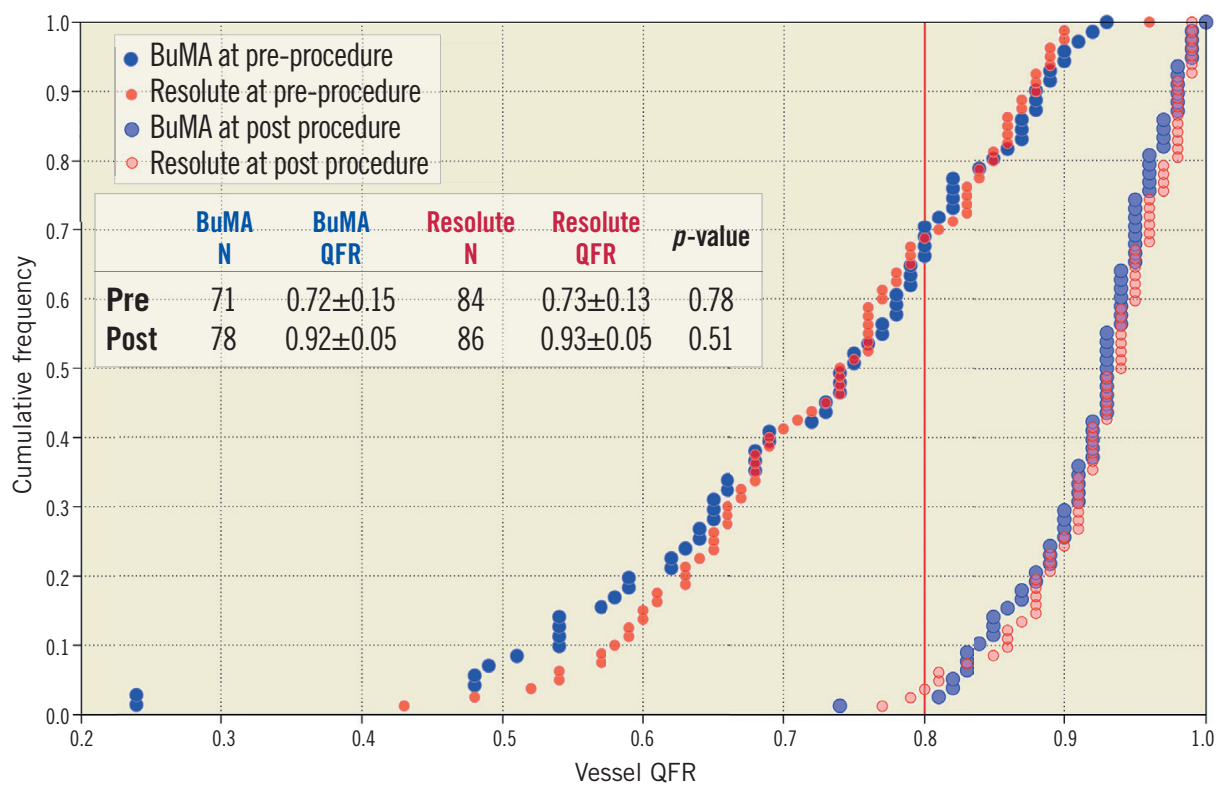

Figure 3. Cumulative frequency distribution curves of vessel QFR pre-procedure and post procedure. Vessel QFR pre-procedure (blue for the BuMA Supreme SES group and red for the Resolute ZES group) and post procedure (light blue for the BuMA Supreme SES group and pink for the Resolute ZES group). N: number of lesions 
Table 1. Results of 2D-QCA analysis.

\begin{tabular}{|c|c|c|c|c|c|c|c|}
\hline & & $\mathbf{N}$ & B-SES & $\mathbf{N}$ & R-ZES & Difference $(95 \%$ CI) & $p$-value \\
\hline \multirow[t]{5}{*}{ Pre-procedure } & Mean lumen diameter (mm) & 71 & $2.25 \pm 0.35$ & 84 & $2.34 \pm 0.42$ & $-0.09[-0.21,0.03]$ & 0.16 \\
\hline & Minimum lumen diameter (mm) & 71 & $1.01 \pm 0.27$ & 84 & $1.04 \pm 0.35$ & $-0.04[-0.14,0.06]$ & 0.47 \\
\hline & Reference lumen diameter (mm) & 71 & $2.55 \pm 0.40$ & 84 & $2.68 \pm 0.49$ & $-0.13[-0.28,0.01]$ & 0.07 \\
\hline & \% Diameter stenosis (\%) & 71 & $60.1 \pm 10.3$ & 84 & $60.7 \pm 10.8$ & $-0.62[-3.99,2.75]$ & 0.72 \\
\hline & Lesion length (mm) & 71 & $13.7 \pm 6.5$ & 84 & $14.7 \pm 7.0$ & $-0.95[-3.11,1.2]$ & 0.38 \\
\hline \multicolumn{8}{|l|}{ In-stent } \\
\hline \multirow[t]{5}{*}{ Post procedure } & Mean lumen diameter (mm) & 78 & $2.81 \pm 0.37$ & 86 & $2.88 \pm 0.40$ & $-0.06[-0.18,0.05]$ & 0.29 \\
\hline & Minimum lumen diameter (mm) & 78 & $2.44 \pm 0.37$ & 86 & $2.45 \pm 0.40$ & $-0.01[-0.13,0.11]$ & 0.92 \\
\hline & Reference lumen diameter (mm) & 78 & $2.71 \pm 0.40$ & 86 & $2.77 \pm 0.44$ & $-0.06[-0.18,0.07]$ & 0.40 \\
\hline & $\%$ Diameter stenosis (\%) & 78 & $9.71 \pm 6.54$ & 86 & $11.4 \pm 5.6$ & $-1.71[-3.59,0.16]$ & 0.07 \\
\hline & Acute gain (mm) & 62 & $1.38 \pm 0.34$ & 73 & $1.43 \pm 0.41$ & $-0.04[-0.17,0.09]$ & 0.53 \\
\hline \multirow[t]{6}{*}{ 9-month follow-up } & Mean lumen diameter (mm) & 82 & $2.62 \pm 0.39$ & 86 & $2.85 \pm 0.49$ & $-0.23[-0.36,-0.1]$ & 0.001 \\
\hline & Minimum lumen diameter (mm) & 82 & $2.13 \pm 0.44$ & 86 & $2.38 \pm 0.51$ & $-0.25[-0.4,-0.11]$ & 0.001 \\
\hline & Reference lumen diameter (mm) & 82 & $2.63 \pm 0.40$ & 86 & $2.81 \pm 0.46$ & $-0.18[-0.31,-0.05]$ & 0.007 \\
\hline & $\%$ Diameter stenosis (\%) & 82 & $17.0 \pm 12.0$ & 86 & $15.5 \pm 11.6$ & $3.49[-0.11,7.08]$ & 0.06 \\
\hline & Binary restenosis & 82 & $3(3.7)$ & 86 & $3(3.5)$ & & 1.00 \\
\hline & Late lumen loss (mm) & 69 & $0.30 \pm 0.34$ & 72 & $0.13 \pm 0.35$ & $0.17[0.05,0.28]$ & 0.004 \\
\hline \multicolumn{8}{|l|}{ In-segment } \\
\hline \multirow[t]{5}{*}{ Post procedure } & Mean lumen diameter (mm) & 78 & $2.74 \pm 0.39$ & 86 & $2.79 \pm 0.41$ & $-0.05[-0.18,0.07]$ & 0.39 \\
\hline & Minimum lumen diameter (mm) & 78 & $2.11 \pm 0.43$ & 86 & $2.15 \pm 0.39$ & $-0.04[-0.16,0.09]$ & 0.55 \\
\hline & Reference lumen diameter (mm) & 78 & $2.62 \pm 0.41$ & 86 & $2.72 \pm 0.46$ & $-0.1[-0.23,0.04]$ & 0.15 \\
\hline & $\%$ Diameter stenosis (\%) & 78 & $19.7 \pm 7.5$ & 86 & $20.7 \pm 7.0$ & $-1.06[-3.3,1.18]$ & 0.35 \\
\hline & Acute gain $(\mathrm{mm})$ & 62 & $1.04 \pm 0.44$ & 73 & $1.13 \pm 0.4$ & $-0.09[-0.23,0.05]$ & 0.21 \\
\hline \multirow[t]{6}{*}{ 9-month follow-up } & Mean lumen diameter (mm) & 82 & $2.60 \pm 0.39$ & 86 & $2.78 \pm 0.47$ & $-0.18[-0.31,-0.05]$ & 0.008 \\
\hline & Minimum lumen diameter (mm) & 82 & $1.96 \pm 0.47$ & 86 & $2.12 \pm 0.48$ & $-0.17[-0.31,-0.02]$ & 0.03 \\
\hline & Reference lumen diameter (mm) & 82 & $2.59 \pm 0.41$ & 86 & $2.77 \pm 0.47$ & $-0.18[-0.31,-0.05]$ & 0.009 \\
\hline & $\%$ Diameter stenosis (\%) & 82 & $24.4 \pm 12.6$ & 86 & $23.3 \pm 11.2$ & $1.13[-2.49,4.76]$ & 0.54 \\
\hline & Binary restenosis & 82 & $5(6.1)$ & 86 & $4(4.7)$ & & 0.74 \\
\hline & Late lumen loss (mm) & 69 & $0.14 \pm 0.38$ & 72 & $0.05 \pm 0.31$ & $0.09[-0.03,0.2]$ & 0.13 \\
\hline
\end{tabular}

Table 2. Results of QFR analysis.

\begin{tabular}{|c|c|c|c|c|c|c|c|}
\hline & & $\mathbf{N}$ & B-SES & $\mathbf{N}$ & R-ZES & Difference $(95 \%$ CI) & $p$-value \\
\hline Pre-procedure & Vessel QFR & 71 & $0.72 \pm 0.15$ & 84 & $0.73 \pm 0.13$ & $-0.006[-0.05,0.04]$ & 0.78 \\
\hline \multirow[t]{2}{*}{ Post procedure } & Vessel QFR & 78 & $0.92 \pm 0.05$ & 86 & $0.93 \pm 0.05$ & $-0.005[-0.02,0.01]$ & 0.51 \\
\hline & In-stent $Q F R$ gradient $\left(\triangle \mathrm{QFR}_{\text {POST }}\right.$ ) & 78 & $0.01 \pm 0.01$ & 86 & $0.01 \pm 0.01$ & $0.001[-0.003,0.00]$ & 0.68 \\
\hline \multirow[t]{4}{*}{ 9-month follow-up } & Vessel QFR & 82 & $0.89 \pm 0.10$ & 86 & $0.89 \pm 0.11$ & $-0.001[-0.03,0.03]$ & 0.97 \\
\hline & Vessel QFR $\leq 0.8$ & 82 & $9(11.0)$ & 86 & $11(12.8)$ & & 0.72 \\
\hline & In-stent $\mathrm{QFR}$ gradient $\left(\triangle \mathrm{QFR} \mathrm{F}_{\mathrm{FU}}\right)$ & 82 & $0.03 \pm 0.04$ & 86 & $0.03 \pm 0.07$ & $-0.001[-0.02,0.02]$ & 0.95 \\
\hline & $\triangle \mathrm{QFR}_{\mathrm{FU}}-\triangle \mathrm{QFR}_{\mathrm{POST}}$ & 69 & $0.01 \pm 0.05$ & 72 & $0.02 \pm 0.07$ & $-0.003[-0.02,0.02]$ & 0.75 \\
\hline
\end{tabular}




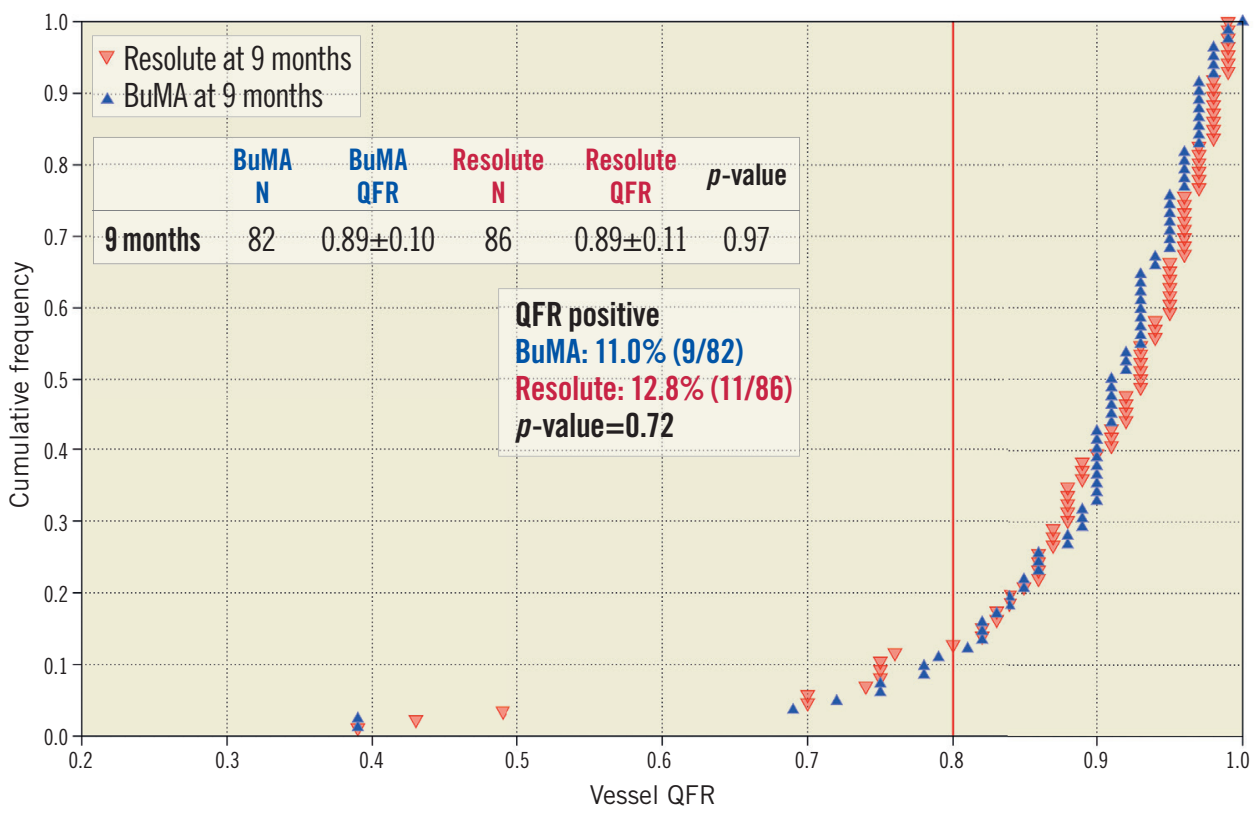

Figure 4. Cumulative frequency distribution curves of vessel QFR at nine months. Vessel QFR at nine-month follow-up (blue for the BuMA Supreme SES group and red for the Resolute ZES group). N: number of lesions

two groups $\left(\Delta \mathrm{QFR}_{\mathrm{FU}}: 0.03 \pm 0.04\right.$ vs. $0.03 \pm 0.07, \mathrm{p}=0.95, \Delta \mathrm{QFR}_{\mathrm{FU}}{ }^{-}$ $\Delta \mathrm{QFR}_{\mathrm{POST}}: 0.01 \pm 0.05$ vs. $0.02 \pm 0.07, \mathrm{p}=0.75$ ). Figure 5 shows the cumulative frequency distribution curves of QFR gradient across the device at nine months $\left(\Delta \mathrm{QFR}_{\mathrm{FU}}\right)$ plotted with binary restenosis.

Figure 6 shows a correlation between in-stent LLL at nine months and difference in QFR gradient across the device between post procedure and follow-up $\left(\Delta \mathrm{QFR}_{\mathrm{FU}}-\Delta \mathrm{QFR}_{\mathrm{POST}}\right)$ with scatter plots, in which a regression curve is drawn. The regression curve shows an unapparent increase of difference in QFR gradient across the device $\left(\Delta \mathrm{QFR}_{\mathrm{FU}}-\Delta \mathrm{QFR}_{\mathrm{POST}}\right)$ within the range of low value of LLL $(<0.50 \mathrm{~mm})$, where the LLLs of both device groups are distributed. In contrast, a sharp increase of difference in QFR gradient across the device is observed once LLL reaches more than $0.70 \mathrm{~mm}$.

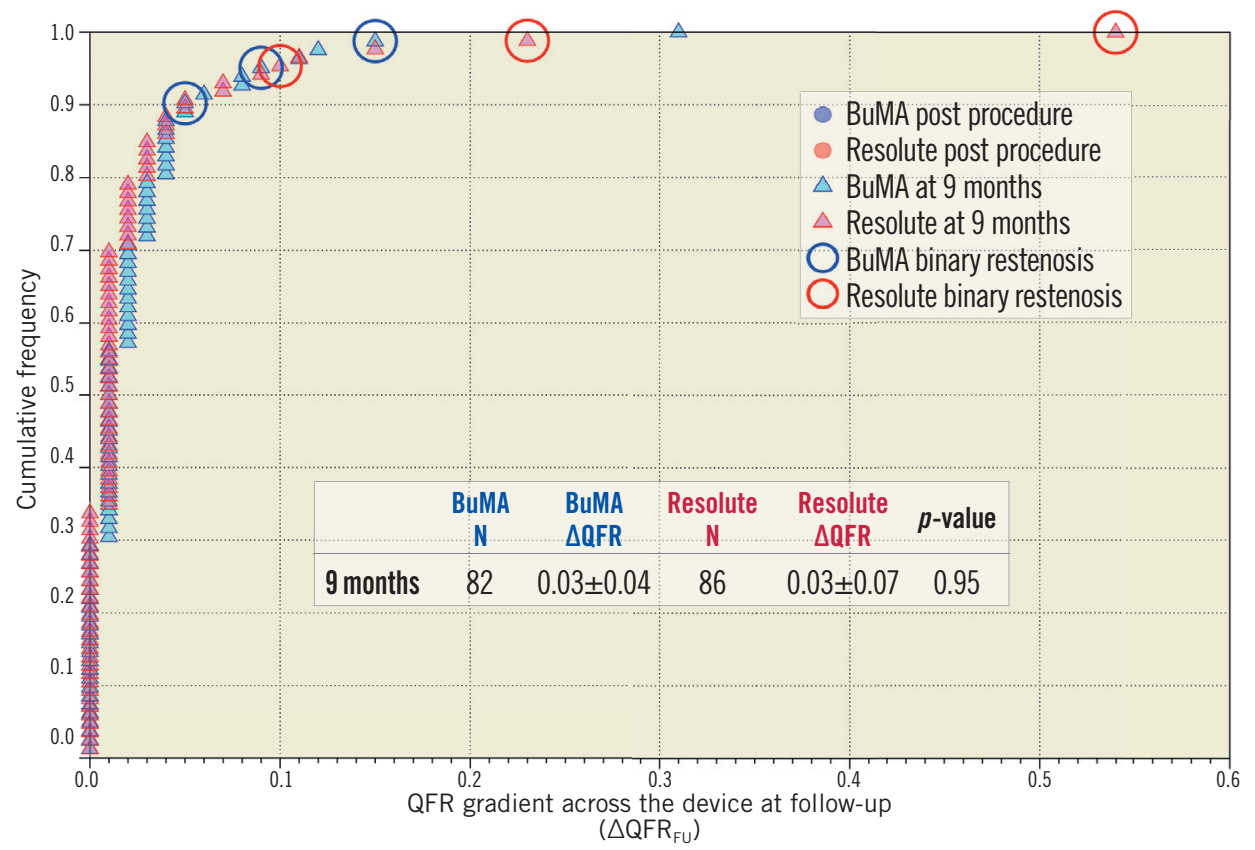

Figure 5. Cumulative frequency distribution curves of in-stent $\triangle Q F R$ at nine months. In-stent $\triangle Q F R$ at nine-month follow-up (light blue for the BuMA Supreme SES group and pink for the Resolute ZES group). Lesions with binary restenosis are indicated with a circle. N: number of lesions 


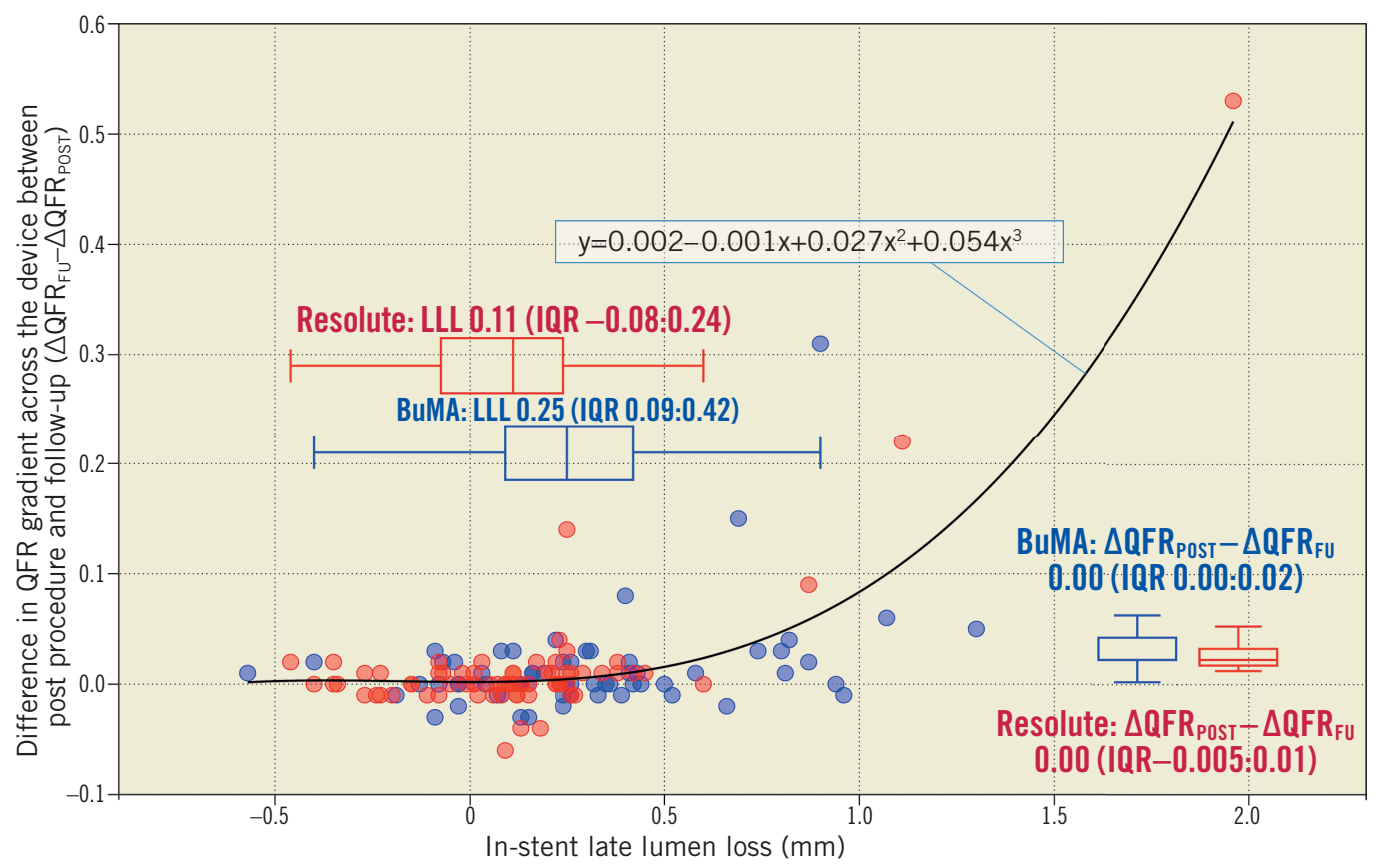

Figure 6. Correlation between difference in QFR gradient across the device and in-stent late lumen loss at nine months. A regression curve is drawn $\left(y=0.002-0.001 x+0.027 x^{2}+0.054 x^{3}, y=\Delta Q F R_{F U}-\triangle Q F R_{P O S T}, x=\right.$ in-stent LLL at nine months). The curve shows an apparent increase in difference in QFR gradient across the device $\left(\triangle Q F R_{F U}-\triangle Q F R_{P O S T}\right)$ within the range of low value LLL $(<0.50 \mathrm{~mm})$, where the LLLs of both device groups are distributed. In contrast, a sharp increase in the difference in QFR gradient across the device is observed once LLL reaches more than $0.70 \mathrm{~mm}$. IQR: interquartile range

\section{Discussion}

The major findings of the current substudy can be summarised as follows: 1) despite the in-stent LLL of the B-SES being significantly larger compared to the R-ZES, vessel QFR and QFR gradient across the device at nine-month follow-up $\left(\Delta \mathrm{QFR}_{\mathrm{FU}}\right)$ in the B-SES arm were comparable to the R-ZES arm; 2) the in-stent LLLs of both groups were still within the range where difference in QFR gradient across the device between post procedure and follow-up $\left(\Delta \mathrm{QFR}_{\mathrm{FU}}-\Delta \mathrm{QFR}_{\mathrm{POST}}\right)$ has no functional repercussions.

\section{D-QCA-BASED FFR AND ANGIOGRAPHIC MEASUREMENT}

The physiological assessment based on 3D-QCA (FFRQCA) has already been validated with sufficient accuracy and reproducibility in several studies comparing it to wire-derived FFR ${ }^{10,11,15,19,20}$. The diagnostic accuracy of the contrast-flow QFR for identifying an FFR of $\leq 0.80$ was reported to be $86 \%$ (95\% CI: $78 \%$ to $93 \%$ ). This was comparable to the QFR value computed with hyperaemia (adenosine-flow QFR), which had a diagnostic accuracy of $87 \%$ (95\% CI: $80 \%$ to $94 \%)^{10}$. In the FAVOR Pilot study and the WIFI II study, the diagnostic performance of QFR was compared to $2 \mathrm{D}$ angiographic measurement ${ }^{10,11}$. The area under the receiver operating characteristic curve (AUC) of contrast-flow QFR to identify a wire-derived FFR of $\leq 0.80$ was larger than $\%$ diameter stenosis (AUC: 0.92 [95\% CI: 0.84-0.97] vs. 0.72 [95\% CI: $0.60-$ 0.82 ] in the FAVOR Pilot study, 0.86 [95\% CI: 0.81-0.91] vs. 0.69 [95\% CI: 0.62-0.76] in the WIFI II study) ${ }^{10,11}$. Tu et al showed the superiority of FFRQCA compared to \% area stenosis derived from $3 \mathrm{D}$ angiography in terms of the predictive ability for a wirederived FFR value of $\leq 0.8$ (AUC: 0.93 vs. 0.73 ) ${ }^{15}$.

In addition to the difference in the concept between QFR and conventional angiographic parameters, the less favourable predictive ability of conventional angiographic parameters for an FFR value of $\leq 0.8$ is also ascribed to the difference of the region of interest (lesion versus vessel). In the current study, the number of lesions with QFR $\leq 0.8$ was higher than that of angiographic binary restenosis (number of QFR $\leq 0.8$ : 9 [11.0\%] in the B-SES group and $11[11.0 \%]$ in the R-ZES group, number of binary restenosis: $3[3.7 \%]$ in the B-SES group versus 3 [3.5\%] in the R-ZES group) (Figure 4). Nevertheless, QFR gradient across the device ( $\triangle \mathrm{QFR}$ ) is more comparable to the conventional angiographic parameter measured in the in-stent region of interest. However, as Figure 5 shows, the discrepancy was still observed between $\Delta \mathrm{QFR}$ and binary restenosis, probably due to the fundamental difference between functional and anatomical assessments.

\section{CLINICAL IMPLICATIONS AND REGULATORY PERSPECTIVE}

Figure 6 shows a discrepancy between in-stent LLL (difference in angiographic minimum lumen diameter between post procedure and follow-up) and $\Delta \mathrm{QFR}_{\mathrm{FU}}-\Delta \mathrm{QFR}_{\mathrm{POST}}$ (difference in $\mathrm{QFR}$ gradient across the device between post procedure and follow-up). As Figure 6 shows, the difference of LLL within the low value range $(<0.50 \mathrm{~mm})$ was less significant from the physiological point of 
view. In this range of LLL, even if there is significant difference in LLL between two devices, the functionality of these devices does not differ. This suggests that LLL, a surrogate for in-stent neointimal growth, may not be directly correlated with the ischaemiadriven revascularisation, especially with low values of LLL.

In a pooled data analysis of 11 stent trials, Pocock et al demonstrated that LLL and the probability of TLR were not correlated linearly but exponentially ${ }^{3}$. LLL with a high value range $(>0.5$ $0.7 \mathrm{~mm}$ ) was associated with an increased probability of TLR, whereas LLL in a low value range was not.

For a quarter of century, LLL has been used as a gold standard to assess the efficacy of coronary devices, not only in clinical studies but also for regulatory purposes ${ }^{21}$. However, this parameter may no longer reflect device efficacy in the current DES era, since the low values of LLL seem to have neither functional significance nor clinical implication ${ }^{3}$. In contrast, low LLL is potentially associated with safety issues such as delayed neointimal healing, evagination and malapposition, which in turn are strongly related with device thrombosis ${ }^{22,23}$. In addition, the efficacy assessment based on the LLL derived from sixto nine-month angiography does not take into account the late "catch-up" phenomenon, which is potentially different among stent designs ${ }^{24}$. In contrast to durable polymer, bioresorbable polymer has the potential to reduce the risk of progressive neointimal hyperplasia in the late phase $\mathrm{e}^{25,26}$.

The optimal parameter validating stent performance should be related to physiological significance and clinical adverse events. Functional assessment based on 3D-QCA has the potential to validate stent performance more fundamentally with less invasiveness and a lower cost compared to wire-derived, although, to date, studies directly evaluating the impact of QFR on clinical outcomes have not been reported. The current post hoc analysis should be considered as hypothesis-generating only and should be prospectively and formally demonstrated.

\section{Study limitations}

The study was mainly designed for evaluating angiographic LLL. The physiological assessment based on QFR is a retrospective and non-pre-specified analysis. The number of data points was limited for drawing the regression curve that estimates the correlation between difference in QFR gradient across the device between post procedure and follow-up and in-stent LLL. The current QFR algorithm is based on the classic equation $(\triangle \mathrm{P}=\mathrm{FV}+\mathrm{SV} 2)$ introduced by Young et al and simplified by Gould et al where $\mathrm{F}$ is the coefficient of pressure loss due to viscous friction in the stenotic segment (Poiseuille's law) and S is the coefficient of pressure loss due to flow separation at the diverging end of the stenosis (Bernoulli's law) ${ }^{10,27-29}$. Using this equation, QFR is calculated based on lesion length, minimum lumen area and reference area derived from two angiographic views and volumetric flow of a single vessel calculated by using frame count ${ }^{10}$. This algorithm is simplified compared to the computational flow dynamics (CFD) using the Navier-Stokes equation.

\section{Conclusions}

In the PIONEER trial, the functional parameter (QFR) did not differ between B-SES and R-ZES at nine-month follow-up, despite a significant difference in in-stent LLL. In the current DES era, QFR may have the potential to serve as a novel type of assessment of device performance.

\section{Impact on daily practice}

In the PIONEER trial, although there was significant difference in nine-month in-stent late lumen loss between B-SES and R-ZES, the functional parameters of QFR did not differ between the two groups. The difference in late lumen loss within the very low value range did not have functional significance. In the current DES era, QFR is potentially a more adequate method for the assessment of device performance.

\section{Guest Editor}

This paper was guest edited by Michail I. Papafaklis, MD, PhD, FESC; Department of Interventional Cardiology, Barts Heart Centre, St Bartholomew's Hospital, London, United Kingdom.

\section{Conflict of interest statement}

P. Serruys, M. Sabate and Y. Onuma are members of the Advisory Board for Abbott Vascular. J. Reiber is the CEO of Medis medical imaging systems and has a part-time appointment at Leiden University Medical Center as Professor of Medical Imaging. C. von Birgelen has been an unpaid consultant to several device-manufacturing companies; his institution, Thoraxcentrum Twente, has received institutional research funding from AstraZeneca, Biotronik, Boston Scientific, and Medtronic. C. Collet has received a research grant from HeartFlow. The other authors have no conflicts of interest to declare. The Guest Editor has no conflicts of interest to declare.

\section{References}

1. Serruys PW, Luijten HE, Beatt KJ, Geuskens R, de Feyter PJ, van den Brand $\mathrm{M}$, Reiber JH, ten Katen HJ, van Es GA, Hugenholtz PG. Incidence of restenosis after successful coronary angioplasty: a time-related phenomenon. A quantitative angiographic study in 342 consecutive patients at 1, 2, 3, and 4 months. Circulation. 1988;77:361-71

2. Mauri L, Orav EJ, Candia SC, Cutlip DE, Kuntz RE. Robustness of late lumen loss in discriminating drug-eluting stents across variable observational and randomized trials. Circulation. 2005;112:2833-9.

3. Pocock SJ, Lansky AJ, Mehran R, Popma JJ, Fahy MP, Na Y, Dangas G, Moses JW, Pucelikova T, Kandzari DE, Ellis SG, Leon MB, Stone GW. Angiographic surrogate end points in drug-eluting stent trials: a systematic evaluation based on individual patient data from 11 randomized, controlled trials. J Am Coll Cardiol. 2008;51:23-32.

4. Morice MC, Colombo A, Meier B, Serruys P, Tamburino C, Guagliumi G, Sousa E, Stoll HP; REALITY Trial Investigators. Sirolimus- vs paclitaxel-eluting stents in de novo coronary artery 
lesions: the REALITY trial: a randomized controlled trial. JAMA. 2006;295:895-904.

5. Kandzari DE, Leon MB, Popma JJ, Fitzgerald PJ, O'Shaughnessy C, Ball MW, Turco M, Applegate RJ, Gurbel PA, Midei MG, Badre SS, Mauri L, Thompson KP, LeNarz LA, Kuntz RE; ENDEAVOR III Investigators. Comparison of zotarolimus-eluting and sirolimus-eluting stents in patients with native coronary artery disease: a randomized controlled trial. J Am Coll Cardiol. 2006;48:2440-7.

6. Pijls NH, van Son JA, Kirkeeide RL, De Bruyne B, Gould KL. Experimental basis of determining maximum coronary, myocardial, and collateral blood flow by pressure measurements for assessing functional stenosis severity before and after percutaneous transluminal coronary angioplasty. Circulation. 1993;87:1354-67.

7. Park SJ, Kang SJ, Ahn JM, Shim EB, Kim YT, Yun SC, Song H, Lee JY, Kim WJ, Park DW, Lee SW, Kim YH, Lee CW, Mintz GS, Park SW. Visual-functional mismatch between coronary angiography and fractional flow reserve. JACC Cardiovasc Interv. 2012;5:1029-36.

8. Tonino PA, De Bruyne B, Pijls NH, Siebert U, Ikeno F, van't Veer M, Klauss V, Manoharan G, Engstrom T, Oldroyd KG, Ver Lee PN, MacCarthy PA, Fearon WF; FAME Study Investigators. Fractional flow reserve versus angiography for guiding percutaneous coronary intervention. N Engl J Med. 2009;360:213-24.

9. De Bruyne B, Pijls NH, Kalesan B, Barbato E, Tonino PA, Piroth Z, Jagic N, Möbius-Winkler S, Rioufol G, Witt N, Kala P, MacCarthy P, Engström T, Oldroyd KG, Mavromatis K, Manoharan G, Verlee P, Frobert O, Curzen N, Johnson JB, Jüni P, Fearon WF; FAME 2 Trial Investigators. Fractional flow reserveguided PCI versus medical therapy in stable coronary disease. N Engl J Med. 2012;367:991-1001.

10. Tu S, Westra J, Yang J, von Birgelen C, Ferrara A, Pellicano M, Nef H, Tebaldi M, Murasato Y, Lansky A, Barbato E, van der Heijden LC, Reiber JH, Holm NR, Wijns W; FAVOR Pilot Trial Study Group. Diagnostic Accuracy of Fast Computational Approaches to Derive Fractional Flow Reserve From Diagnostic Coronary Angiography: The International Multicenter FAVOR Pilot Study. JACC Cardiovasc Interv. 2016;9:2024-35.

11. Westra J, Tu S, Winther S, Nissen L, Vestergaard MB, Andersen BK, Holck EN, Fox Maule C, Johansen JK, Andreasen LN, Simonsen JK, Zhang Y, Kristensen SD, Maeng M, Kaltoft A, Terkelsen CJ, Krusell LR, Jakobsen L, Reiber JHC, Lassen JF, Bottcher M, Botker HE, Christiansen EH, Holm NR. Evaluation of Coronary Artery Stenosis by Quantitative Flow Ratio During Invasive Coronary Angiography: The WIFI II Study (Wire-Free Functional Imaging II). Circ Cardiovasc Imaging. 2018;11:e007107.

12. van Rosendael AR, Koning G, Dimitriu-Leen AC, Smit JM, Montero-Cabezas JM, van der Kley F, Jukema JW, Reiber JHC, Bax JJ, Scholte AJHA. Accuracy and reproducibility of fast fractional flow reserve computation from invasive coronary angiography. Int J Cardiovasc Imaging. 2017;33:1305-12.

13. Yazaki K, Otsuka M, Kataoka S, Kahata M, Kumagai A, Inoue K, Koganei H, Enta K, Ishii Y. Applicability of 3-Dimensional
Quantitative Coronary Angiography-Derived Computed Fractional Flow Reserve for Intermediate Coronary Stenosis. Circ J. 2017; 81:988-92.

14. von Birgelen $\mathrm{C}$, Asano $\mathrm{T}$, Amoroso $\mathrm{G}$, Aminian $\mathrm{A}$, Brugaletta S, Vrolix M, Hernandez-Antolin R, van de Harst P, Iñiguez A, Janssens L, Smits PC, Wykrzykowska JJ, Ribeiro VG, Pereira H, da Silva PC, Piek JJ, Onuma Y, Serruys PW, Sabaté M. First-in-man randomised comparison of the BuMA Supreme biodegradable polymer sirolimus-eluting stent versus a durable polymer zotarolimus-eluting coronary stent: the PIONEER trial. EuroIntervention. 2018;13:2026-35.

15. Tu S, Barbato E, Köszegi Z, Yang J, Sun Z, Holm NR, Tar B, Li Y, Rusinaru D, Wijns W, Reiber JH. Fractional flow reserve calculation from 3-dimensional quantitative coronary angiography and TIMI frame count: a fast computer model to quantify the functional significance of moderately obstructed coronary arteries. JACC Cardiovasc Interv. 2014;7:768-77.

16. Tu S, Xu L, Ligthart J, Xu B, Witberg K, Sun Z, Koning G, Reiber JH, Regar E. In vivo comparison of arterial lumen dimensions assessed by co-registered three-dimensional (3D) quantitative coronary angiography, intravascular ultrasound and optical coherence tomography. Int J Cardiovasc Imaging. 2012;28:1315-27.

17. Gibson CM, Cannon CP, Daley WL, Dodge JT Jr, Alexander B Jr, Marble SJ, McCabe CH, Raymond L, Fortin T, Poole WK, Braunwald E. TIMI frame count: a quantitative method of assessing coronary artery flow. Circulation. 1996;93:879-88.

18. Onuma Y, Dudek D, Thuesen L, Webster M, Nieman K, Garcia-Garcia HM, Ormiston JA, Serruys PW. Five-year clinical and functional multislice computed tomography angiographic results after coronary implantation of the fully resorbable polymeric everolimus-eluting scaffold in patients with de novo coronary artery disease: the ABSORB cohort A trial. JACC Cardiovasc Interv. 2013;6:999-1009.

19. Papafaklis MI, Muramatsu T, Ishibashi Y, Lakkas LS, Nakatani S, Bourantas CV, Ligthart J, Onuma Y, Echavarria-Pinto M, Tsirka G, Kotsia A, Nikas DN, Mogabgab O, van Geuns RJ, Naka KK, Fotiadis DI, Brilakis ES, Garcia-Garcia HM, Escaned J, Zijlstra F, Michalis LK, Serruys PW. Fast virtual functional assessment of intermediate coronary lesions using routine angiographic data and blood flow simulation in humans: comparison with pressure wire - fractional flow reserve. EuroIntervention. 2014;10:574-83.

20. Yong AS, Ng AC, Brieger D, Lowe HC, Ng MK, Kritharides L. Three-dimensional and two-dimensional quantitative coronary angiography, and their prediction of reduced fractional flow reserve. Eur Heart J. 2011;32:345-53.

21. Byrne RA, Serruys PW, Baumbach A, Escaned J, Fajadet J, James S, Joner M, Oktay S, Jüni P, Kastrati A, Sianos G, Stefanini GG, Wijns W, Windecker S. Report of a European Society of Cardiology-European Association of Percutaneous Cardiovascular Interventions task force on the evaluation of coronary stents in Europe: executive summary. Eur Heart J. 2015;36:2608-20.

22. Radu MD, Räber L, Kalesan B, Muramatsu T, Kelbaek H, Heo J, Jorgensen E, Helqvist S, Farooq V, Brugaletta S, 
Garcia-Garcia HM, Jüni P, Saunamäki K, Windecker S, Serruys PW. Coronary evaginations are associated with positive vessel remodelling and are nearly absent following implantation of newer-generation drug-eluting stents: an optical coherence tomography and intravascular ultrasound study. Eur Heart J. 2014;35:795-807.

23. Souteyrand G, Amabile N, Mangin L, Chabin X, Meneveau N, Cayla G, Vanzetto G, Barnay P, Trouillet C, Rioufol G, Rangé G, Teiger E, Delaunay R, Dubreuil O, Lhermusier T, Mulliez A, Levesque S, Belle L, Caussin C, Motreff P; PESTO Investigators. Mechanisms of stent thrombosis analysed by optical coherence tomography: insights from the national PESTO French registry. Eur Heart J. 2016;37:1208-16.

24. Byrne RA, Iijima R, Mehilli J, Pinieck S, Bruskina O, Schömig A, Kastrati A. Durability of antirestenotic efficacy in drug-eluting stents with and without permanent polymer. JACC Cardiovasc Interv. 2009;2:291-9.

25. Lansky AJ, Kastrati A, Edelman ER, Parise H, Ng VG, Ormiston J, Wijns W, Byrne RA. Comparison of the Absorbable Polymer Sirolimus-Eluting Stent (MiStent) to the Durable Polymer Everolimus-Eluting Stent (Xience) (from the DESSOLVE I/II and ISAR-TEST-4 Studies). Am J Cardiol. 2016;117:532-8.

26. Stefanini GG, Byrne RA, Serruys PW, de Waha A, Meier B, Massberg S, Jüni P, Schömig A, Windecker S, Kastrati A.
Biodegradable polymer drug-eluting stents reduce the risk of stent thrombosis at 4 years in patients undergoing percutaneous coronary intervention: a pooled analysis of individual patient data from the ISAR-TEST 3, ISAR-TEST 4, and LEADERS randomized trials. Eur Heart J. 2012;33:1214-22.

27. Young DF, Tsai FY. Flow characteristics in models of arterial stenoses. I. Steady flow. J Biomech. 1973;6:395-410.

28. Young DF, Tsai FY. Flow characteristics in models of arterial stenoses. II. Unsteady flow. J Biomech. 1973;6:547-59.

29. Serruys PW, Girasis C, Papadopoulou SL, Onuma Y. Noninvasive fractional flow reserve: scientific basis, methods and perspectives. EuroIntervention. 2012;8:511-9.

\section{Supplementary data}

Supplementary Appendix. Inclusion and exclusion criteria of the PIONEER trial.

Supplementary Table 1. Baseline characteristics in the PIONEER trial.

The supplementary data are published online at:

http://www.pcronline.com/

eurointervention/138th issue/100 


\section{Supplementary data}

\section{Supplementary Appendix. Inclusion and exclusion criteria of the PIONEER trial.}

Patients were eligible for study enrolment if they met the eligibility criteria, listed below: age 18 years or older; presence of stable or unstable angina or silent ischaemia with clinical evidence of ischaemic heart disease and/or positive territorial functional study; presence of one or two separate, de novo target lesions (a single target lesion per major epicardial territory) with a 50-99\% lumen diameter stenosis in a reference vessel of 2.5-4.5 mm (visually determined), and a target lesion length that allowed treatment with a single study stent; coronary flow grade 2 or 3 according to the Thrombolysis In Myocardial Infarction (TIMI) classification in all target vessels.

Patients were not eligible if they met at least one of the following exclusion criteria: female of child-bearing potential; evolving myocardial infarction; bifurcated target lesion involving a side branch $>2.0 \mathrm{~mm}$; target lesion in the left main artery; aorto-ostial target lesion; target lesion with the presence of angiographically visible thrombus; restenotic target lesion; left ventricular ejection fraction $<30 \%$; renal insufficiency (e.g., serum creatinine $>2.5 \mathrm{mg} / \mathrm{dL}$, creatinine clearance $\leq 30 \mathrm{~mL} / \mathrm{min}$, or patient treated by dialysis); intolerance for aspirin, heparin, antiplatelet medication specified for use in the study, sirolimus, zotarolimus, or cobalt-chromium. 


\begin{tabular}{|c|c|c|c|}
\hline \multicolumn{4}{|c|}{ Supplementary Table 1. Baseline characteristics in the PIONEER trial. } \\
\hline & $\begin{array}{c}\text { B-SES } \\
(\mathrm{N}=83)\end{array}$ & $\begin{array}{l}\text { R-ZES } \\
(\mathbf{N}=87)\end{array}$ & $\begin{array}{c}\text { Difference } \\
\text { [95\% CI] }\end{array}$ \\
\hline Age, years & $64.3 \pm 8.9$ & $62.5 \pm 9.3$ & $1.7[-1.0,4.5]$ \\
\hline Male sex & $62(74.7)$ & $64(73.6)$ & $1.1[-12.0,14.3]$ \\
\hline BMI & $27.8 \pm 4.8$ & $27.8 \pm 4.2$ & $0.1[-1.3,1.4]$ \\
\hline \multicolumn{4}{|l|}{ Coexisting condition } \\
\hline Diabetes mellitus & 24 (28.9) & $20(23)$ & $5.9[-7.2,19.1]$ \\
\hline Insulin-treated diabetes & $10(12.0)$ & $6(6.9)$ & $5.2[-3.6,13.9]$ \\
\hline Non-insulin-treated diabetes & 14 (16.9) & $14(16.1)$ & $0.8[-10.4,11.9]$ \\
\hline Hypertension & $47(56.6)$ & $57(65.5)$ & $-8.9[-23.5,5.7]$ \\
\hline 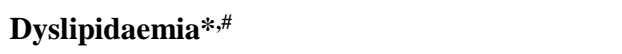 & $54(65.1)$ & $53(61.6)$ & $3.4[-11.1,18.0]$ \\
\hline \multicolumn{4}{|l|}{ Current or previous smoker } \\
\hline Current smoker*,\# & $21(25.6)$ & $22(25.6)$ & \\
\hline Previous smoker*,\# & $35(42.7)$ & $35(40.7)$ & \\
\hline Family history of CAD*,\# & $35(42.7)$ & $37(43.0)$ & $-0.3[-15.3,14.6]$ \\
\hline Previous myocardial infarction & 15 (18.1) & $15(17.2)$ & $0.8[-10.6,12.3]$ \\
\hline Previous percutaneous coronary intervention & $18(21.7)$ & $16(18.4)$ & $3.3[-8.7,15.3]$ \\
\hline Previous coronary artery bypass grafting & $4(4.8)$ & $3(3.4)$ & $1.4[-4.6,7.4]$ \\
\hline COPD & $5(6.0)$ & $4(4.6)$ & $1.4[-5.3,8.2]$ \\
\hline \multicolumn{4}{|l|}{ Initial clinical presentation } \\
\hline Unstable angina & $20(24.1)$ & $15(17.2)$ & \\
\hline Stable angina & $42(50.6)$ & $52(59.8)$ & \\
\hline Silent ischaemia & $21(25.3)$ & $20(23.0)$ & \\
\hline
\end{tabular}

Data are expressed as mean $\pm \mathrm{SD}$ or number (percentage).

* Missing data for one patient in B-SES arm; * missing data for one patient in R-ZES arm.

BMI: body mass index; CAD: coronary artery disease; COPD: chronic obstructive pulmonary disease 